$16^{\text {th }}$ International Congress of Metrology, 06009 (2013)

DOI: $10.1051 /$ metrology/201306009

(c) Owned by the authors, published by EDP Sciences, 2013

\title{
INTER-LABORATORY COMPARISONS WITH THE CALIBRATION OF GEODETIC INSTRUMENTS
}

\author{
Jelena Gučević ${ }^{1, a}$, Siniša Delčev ${ }^{1}$ and Vukan Ogrizović ${ }^{1}$ \\ ${ }^{1}$ University of Belgrade, Faculty of Civil Engineering, Department of Geodesy and Geoinformatics, Belgrade, Serbia
}

\begin{abstract}
This paper presents the elements of metrology laboratory accreditation for calibration in the scope of calibration E-05 dimensions, and calibration for the subject: distance and angle measures. Within the technical requirements for the competence of calibration laboratories (ISO/IEC 17025:2006), the requirements relating to the providing confidence in the quality of the results of the calibration are defined. Each laboratory must have the quality management procedures for monitoring the validity of the calibrations performed. This monitoring will be planned and reviewed through: internal quality control, participation in the inter-laboratory comparisons or proficiency testing schemes, repeated calibrations using the same or different methods, recalibration of the saved samples and correlation of results for different characteristics of the sample. The procedure and the results of the inter-laboratory comparisons between two accredited laboratories will be described in particular: Metrological Laboratory for Angle and Length Calibration, Faculty of Civil Engineering, University of Belgrade (ML160), and Metrological Laboratory of High Construction-Surveying School to Professional Studies (MLVGGS). Comparing results are analysed within the defined criteria with pre-planned effort to solve the problem and prevent incorrect results that appear in the report. The procedures are based on the application of best practice solutions. Since the ML160 laboratory was included in the family of accredited laboratories, the laboratory staff has been putting great effort to ensure the quality of work and the quality control of the work, in accordance with the requirements of ISO/IEC 17025:2006. In order to maintain their competency the ML160 laboratory conducts internal and external quality control. This paper will present the inter-laboratory comparisons as a form of external quality control in which the ML160 laboratory has participated.
\end{abstract}

\section{Introduction}

Ensuring confidence in the quality of testing and calibration results in accordance with the general requirements (ISO/IEC 17025:2005) implies that: "The laboratory shall have quality control procedures for monitoring the validity of tests and calibrations undertaken. The resulting data shall be recorded in such a way that trends are detectable and, where practicable, statistical techniques shall be applied to the reviewing of the results. This monitoring shall be planned and reviewed and may include, but not be limited to, the following:

a) regular use of certified reference materials and/or internal quality control using secondary reference materials;

b) participation in inter-laboratory comparison or proficiency-testing programmes;

c) replicate tests or calibrations using the same or different methods;

d) retesting or recalibration of retained items; e) correlation of results for different characteristics of an item.

Quality control data shall be analysed and, where they are found to be outside pre-defined criteria, planned action shall be taken to correct the problem and to prevent incorrect results from being reported."

In order to maintain their competency the ML160 laboratory conducts internal and external quality control. This paper will present the inter-laboratory comparisons as a form of external quality control in which the ML160 laboratory has participated.

\section{Inter-laboratory comparison}

Participation in inter-laboratory comparisons provides to participating laboratories an objective way of evaluation and presentation of data reliability. In accordance with the standard (ISO/IEC 17043:2010) Inter-laboratory Comparison is the organisation, implementation and evaluation of test results of the same or similar testing objects/samples by two or more laboratories in

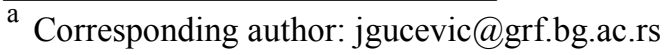


accordance with predetermined conditions. This is an important activity of the laboratory and the result of participation in certain testing conditions is the data that testifies to the laboratory competence. The result analysis of inter-laboratory comparisons should provide data on: the number of participating laboratories, the number of calibration samples; it should describe the obtained values, their accuracy and differences. The obtained values should be set to allow proper result evaluation of participating laboratories.

Common types of inter-laboratory comparisons are:

1. inter-laboratory comparison using the technique of successive testing, when the participating laboratories in sequence, and according to the predetermined order, perform testing of the same sample. The disadvantages of this comparison are the long testing time. This comparison requires steadiness and stability, as well as the homogeneity of the sample.

2. inter-laboratory comparison using the technique of comparative testing, when the participating laboratories simultaneously perform testing of the same sample, during the period predetermined by the organisers. For this comparison the sample homogeneity is essential.

3. inter-laboratory comparison using the technique of sharing a sample, most commonly used by laboratory users. In this case, the sample is tested in two participating laboratories simultaneously. It is desirable that the user saves another sample for the "third" laboratory, in case of significant differences between the test results. This procedure is known as "super-analysis".

Implementation, participation, as well as the effect of inter-laboratory comparisons, is an important evidence for the laboratories when assessing the technical competency by the accreditation body. During the processing of the results obtained in the inter-laboratory comparison it is necessary to consider: the number of participating laboratories, the number of test samples and the number of repeated tests on each sample, assessment of assigned values, assessment of inconsistent values, precision and accuracy of the obtained results and the differences between the participating laboratories at the desired level of confidence [11].

For the statistical analysis of the results obtained in inter-laboratory comparison, the procedures described in the section B.3 Calculation of performance statistics (ISO/IEC 17043:2010) are used. The results obtained in inter-laboratory comparison are transformed in $z$ result and in $E$.

$$
\begin{gathered}
z=\frac{x-X}{\sigma} \\
E=\frac{x-X}{2 \sqrt{U_{l a b}^{2}+U_{r e f}^{2}}}
\end{gathered}
$$

where:

$x$ - participants' results,

$X$ - the assigned value, $\sigma$ - standard deviation for proficiency assessment (measure of dispersion used in the evaluation of results of proficiency testing, based on the available information),

$U_{l a b}$ - is the expanded uncertainty of a participant's results,

$U_{\text {ref }}$ - is the expanded uncertainty of the reference laboratory's assigned value.

Decision is made according to the result:

1) for $z$ scores:

$|z| \leq 2.0$ indicates "satisfactory" performance and no signal,

$2.0<|z|<3.0 \quad$ indicates "questionable"

performance and generates a warning signal,

$|z|>3.0$ indicates "unsatisfactory" performance and generates an action signal.

2) for $E$ scores:

$\left|E_{n}\right| \leq 1.0$ indicates "satisfactory" performance and no signal,

$\left|E_{n}\right|>1.0$ indicates "unsatisfactory" performance and generates an action signal.

\section{Calibration of geodetic instruments}

The Metrology Law of the Republic of Serbia [8] governs metrology, legal units of measurement and standards of the Republic of Serbia. Professional services for the Republic of Serbia in the field of metrology are performed by the Directorate of Measures and Precious Metals. Accreditation Body of Serbia (ATS) is the only body in the Republic of Serbia, where the Accreditation Act entrusts the performance of accreditation that establishes the competency of:

- testing laboratories;

- calibration laboratories;

- medical laboratories;

- organisations that carry out inspection activities, and

- certification bodies for certification of products and processes, management systems and experts.

The Law on State Survey and Cadastre of the Republic of Serbia [7] covers metrological provision of geodetic work and standardisation. Metrological provision implies the establishment of metrological characteristics of surveying instruments before use in the state survey and real estate and power lines cadastre maintenance. Surveying instruments are subject to the first examination of measures, periodic and emergency examination of measures, which is evidenced by a certificate of an accredited laboratory.

In the process of the laboratory accreditation:

- ML160 - Metrological Laboratory for Angle and Length Calibration, Faculty of Civil Engineering, Belgrade University and

- MLVGGS - Metrological Laboratory of High Construction-Surveying School to Professional Studies, 
have proved their competency and thereby committed themselves to ensure quality system in the field of dimension calibration. Laboratories are accredited for length and angle calibrations in geodesy and meet the requirements of ISO/IEC 17025:2005. The ML-160 and MLVGGS laboratories participate in inter-laboratory comparisons in order to identify possible defects in laboratory practices necessary to enhance operations, identify reliability of methods, materials and equipment and suggest corrective measures. The proper evaluation of the results of inter-laboratory comparisons was performed for different testing subjects. Time, subject and parameters of the testing are presented in Table 1.

Table 1. Epoch of inter-laboratory comparision.

\begin{tabular}{|l|l|l|}
\hline Epoch & Testing subject & Determined parameters \\
\hline 2010 & $\begin{array}{l}\text { Electro-optical } \\
\text { distance-meter }\end{array}$ & Additive constant \\
\hline 2011 & $\begin{array}{l}\text { Levelling with } \\
\text { levelling rod }\end{array}$ & Measurement uncertainty \\
\hline 2012 & GPS antenna & Antenna phase centre variation \\
\hline 2013 & Theodolite & $\begin{array}{l}\text { collimation, inclination of the } \\
\text { spin axis, vertical index } \\
\text { position, measurement } \\
\text { uncertainty of horizontal } \\
\text { angles, measurement } \\
\text { uncertainty of vertical angles }\end{array}$ \\
\hline
\end{tabular}

Table 2. Subject of calibration.

\begin{tabular}{|l|l|}
\hline $\begin{array}{l}\text { Electro-optical } \\
\text { distance-meter: } \\
\text { Sokkia SET630R, } \\
\text { s.n.141055 }\end{array}$ & $\begin{array}{l}\text { Levelling: } \\
\text { Leica SPRINTER 100M, } \\
\text { s.n. 2003275 }\end{array}$ \\
\hline & \\
\hline
\end{tabular}

Evaluation of certain parameters implied the determination of the testing value, according to the method by which the calibration is done. The results obtained in the inter-laboratory comparison are transformed into statistical values for easier interpretation and comparison. The instruments that represented the subject of calibration are shown in Table 2.

\subsection{Distance-meter calibration}

Inter-comparison was performed by determining additive constant of electromagnetic distance-meter and comparing the results. Both inter-comparison participants used the same electromagnetic distance-meter and the same corresponding prism provided by the ML160 laboratory. The instrument SOKKIA SET630R, whose determination of additive constant was the subject of inter-comparison, measures lengths and angles. Measuring uncertainty of length, expressed as a standard deviation, has the form:

$$
\sigma_{d}=a+b \cdot D
$$

where $a$ denotes additive part of standard deviation in $\mathrm{mm}, b$ is its multiplicative part in $\mathrm{mm} / \mathrm{km}$, and $D$ is measured length in $\mathrm{km}$. Standard deviation is thus obtained in $\mathrm{mm}$.

Additive constant in both laboratories is determined in the same way - on the basis of measurements of standard lengths. In the pilot ML160 laboratory [9] four lengths were measured five times (before and after the intercomparison) and in the participant MLVGGS laboratory one length was measured 192 times. Comparison of the results of determining the additive constant of distancemeter is presented in Table 3 .

Table 3. : Comparison of results (all results are expressed in $\mathrm{mm})$.

\begin{tabular}{|c|r|r|r|r|r|r|}
\hline \multirow{2}{*}{ No. } & \multicolumn{2}{|c|}{ ML160 } & \multicolumn{2}{c|}{ MLVGGS } & \multicolumn{2}{c|}{ Difference } \\
\cline { 2 - 7 } & $\begin{array}{c}a_{G F} \\
\mathrm{ML160}\end{array}$ & $\begin{array}{c}U \\
\sigma_{a_{G F}} \cdot 2\end{array}$ & $a_{V G G S}$ & $\begin{array}{c}U \\
a_{a_{V G}} \cdot 2\end{array}$ & $\Delta a$ & $E$ \\
\hline 1. & 0,99 & 0,70 & 0,72 & 1,04 & 0,27 & 0,21 \\
\hline 2. & 0,94 & 1,00 & 0,72 & 1,04 & 0,22 & 0,15 \\
\hline
\end{tabular}

The degree of the result compliance in determining distance-meter additive constant is calculated according to $E$ (expression 2). Measurement uncertainties are determined in accordance with ISO/IEC 17043:2010, Guide to the Expression of Uncertainty. The measurement results shown in Table 3 indicate high conformity in determining the additive constant. The difference in the value of certain additive constant in both laboratories is about $25 \%$. Due to the additive constant values and measurement uncertainty of its determination in both laboratories it can be concluded that by calibration it is determined that there is no additive constant (the constant value is less than the measurement uncertainty). 


\subsection{Levelling calibration}

Both participants of inter-comparison used the same instrument: Leica Geosystems, type SPRINTER 100M, provided by the MLVGGS laboratory. Calibration was performed using the methods:

- DIN 18723, Teil 2 - MLVGGS

- ISO 17123-2 - ML160.

Within the measurement, the measurement uncertainty of the levelled height difference of $1 \mathrm{~km}$ was determined. Comparison of the results is presented in Table 4.

Table 4. Comparison of results.

\begin{tabular}{|c|c|c|}
\hline ML160 & MLVGGS & Conformity test \\
\hline $\begin{array}{c}U \\
\left(\sigma_{G F}\right) \\
{[\mathrm{mm} / \sqrt{\mathrm{km}}]}\end{array}$ & $\begin{array}{c}U \\
\left(\sigma_{V G G S}\right) \\
{[\mathrm{mm} / \sqrt{\mathrm{km}}]}\end{array}$ & $F=\frac{\sigma_{G F}}{\sigma_{V G G S}}$ \\
\hline 0.85 & 0,78 & $1,09<2,22$ \\
\hline
\end{tabular}

Based on the inter-laboratory comparative measurements of the aforementioned methods, we can conclude that the results derived from measurements of the participants in the inter-laboratory comparisons are in conformity. The calculated measurement uncertainty $\sigma_{G F}$ should be tested with the measurement uncertainly $\sigma_{V G G S}$.

Null hypothesis is tested:

$$
H_{0}: \sigma_{V G G S}=\sigma_{G F}
$$

Versus the alternative hypothesis:

$$
H_{1}: \sigma_{V G G S}>\sigma_{G F} \text { and }-H_{2}: \sigma_{V G G S} \neq \sigma_{G F}
$$

Quotient is formed:

$$
F=\frac{\sigma_{G F}}{\sigma_{V G G S}}, \text { for }\left(\sigma_{V G G S}>\sigma_{G F}\right),
$$

where: $F \approx F\left(f_{1}, f_{2}\right) \mid H_{0}$.

Decision test:

$F \leq q, H_{0}$ is accepted; $F>q, H_{0}$ is not accepted where: $q=F_{1-\alpha}\left(f_{1}, f_{2}\right)$

If the previous condition is met the null hypothesis is accepted, which means that the results derived from measurements of the participants of the inter-laboratory comparison are in conformity. If the result is not in accordance with the test statistics, it points to the need to find the cause of deviations and resolve it. The results in this range are considered unacceptable or unsatisfactory, and certainly require reconsideration.

By comparing dispersions, we get: $F=1.09$, for the probability $p=0.95 \%$ and the number of degrees of freedom $\quad f_{1}=f_{2}=f=2 \cdot(\mathrm{n}-1)=2 \cdot(10-1)=18$. $F \approx F\left(f_{1}, f_{2}\right) \mid H_{0}=2,22$, which means that the results derived from the measurements of the participants of inter-laboratory comparisons are in conformity.

\subsection{GPS antenna calibration}

Inter-comparison was performed by determining the variations of the antenna phase centre position and comparing differences. Both inter-comparison participants used their base and the same instrument: LEICA, type SR20, serial number 30669, LEICA AT501 antenna provided by the MLVGGS laboratory based on the methods:

- VDM 01 - MLVGGS,

- UNAVCO (2001): UNAVCO Academic Research Infrastructure (ARI) Receiver and Antenna Test Report - ML160.

The used criteria for evaluation were the expanded measurement uncertainty for each group of measurements and each method [10]. Measurement uncertainties were determined in accordance with ISO / IEC 17043:2010 Guide to the Expression of Uncertainty and the results are presented in Table 5. The conformity level was calculated through $E$ (expression 2).

Table 5. Comparison of calibration results.

\begin{tabular}{|l|c|c|}
\hline \multicolumn{1}{|c|}{ Results } & ML160 & VGGS - \\
\hline $\begin{array}{l}\text { Antenna phase } \\
\text { centre variation }\end{array}$ & $\Delta_{\mathrm{fcGF}}=4,0 \mathrm{~mm}$ & $\Delta_{\mathrm{fcVGGS}}=4,5 \mathrm{~mm}$ \\
\hline $\begin{array}{l}\text { Measurement } \\
\text { uncertainty }\end{array}$ & $\begin{array}{c}\mathrm{U}=2,68 \mathrm{~mm} \\
(k=2)\end{array}$ & $\begin{array}{c}\mathrm{U}=3,22 \mathrm{~mm} \\
(k=2)\end{array}$ \\
\hline Conformity level $E$ & \multicolumn{2}{|c|}{0,06} \\
\hline
\end{tabular}

Based on the inter-laboratory comparative measurements with the mentioned method, we can conclude that the results of the antenna phase centre variations obtained at the reference laboratories ML160 and VGGS are in conformity.

\subsection{Theodolite calibration}

Inter-comparison was performed by determining: collimation, inclination of the spin axis, vertical index position, measurement uncertainty of horizontal angles and measurement uncertainty of vertical angles. Both inter-comparison participants used the same theodolite ZEISS THEO010A provided by the ML160 laboratory. Calibration was performed using the methods:

- DIN 18723, Teil 3 - MLVGGS,

- ISO 17123-3:2001 - ML160.

Table 6 shows comparison of calibration results.

The conformity level was calculated through $E=\frac{\mathrm{x}-\mathrm{X}}{2 \sqrt{U_{l a b}^{2}+U_{r e f}^{2}}}$, where $x, X$ appropriate values that are compared.

Conformity of measurement uncertainty of horizontal and vertical angles was done by testing dispersion conformity (expression 5), for the probability of $95 \%$ and the corresponding number of degrees of freedom $-f_{i}$. 
Table 6. Comparison of calibration results.

\begin{tabular}{|c|c|c|}
\hline Results & ML160 & MLVGGS \\
\hline Collimation & $c=-1,65^{\prime \prime}$ & $c=-1,48^{\prime \prime}$ \\
\hline $\begin{array}{l}\text { Measurement } \\
\text { uncertainty }\end{array}$ & $\begin{array}{c}U=1,20 " \\
(k=2)\end{array}$ & $\begin{array}{c}U=1,33 " \\
(k=2)\end{array}$ \\
\hline Conformity level $E$ & \multicolumn{2}{|c|}{0,05} \\
\hline $\begin{array}{l}\text { Inclination of the spin } \\
\text { axis }\end{array}$ & $\mathrm{i}=1,00^{\prime \prime}$ & $\mathrm{i}=1,09^{\prime \prime}$ \\
\hline $\begin{array}{l}\text { Measurement } \\
\text { uncertainty }\end{array}$ & $\begin{array}{c}U=4,73 " \\
(k=2)\end{array}$ & $\begin{array}{c}U=1,87 " \\
(k=2)\end{array}$ \\
\hline Conformity level $E$ & \multicolumn{2}{|c|}{0,01} \\
\hline Vertical index position & $\mathrm{V}=14,56 "$ & $\mathrm{~V}=15,84^{\prime \prime}$ \\
\hline $\begin{array}{l}\text { Measurement } \\
\text { uncertainty }\end{array}$ & $\begin{array}{c}U=3,38^{\prime \prime} \\
(k=2)\end{array}$ & $\begin{array}{c}U=2,45^{\prime \prime} \\
(k=2)\end{array}$ \\
\hline Conformity level $E$ & \multicolumn{2}{|c|}{0,15} \\
\hline $\begin{array}{l}\text { Measurement } \\
\text { uncertainty of horizontal } \\
\text { angles }(k=2)\end{array}$ & $0,92^{\prime \prime}, f=15$ & $0,95^{\prime \prime}, f=12$ \\
\hline Conformity level & \multicolumn{2}{|c|}{$F=1,033<q=2,62$} \\
\hline $\begin{array}{l}\text { Measurement } \\
\text { uncertainty of vertical } \\
\text { angles }(k=2)\end{array}$ & $0,92^{\prime \prime}, f=15$ & $0,92 ", f=12$ \\
\hline Conformity level & \multicolumn{2}{|c|}{$F=1,00<q=2,62$} \\
\hline
\end{tabular}

On the basis of inter-laboratory comparative measurements by the aforementioned methods, we can conclude that the results obtained in the reference laboratory of inter-laboratory comparison participants are in conformity.

\section{Discussion and conclusions}

Monitoring the quality of the results, the conformity assessment body, is achieved by including in the programmes: inter-laboratory comparison-ILC and proficiency testing - PT. The quality of results can be also monitored by internal measures of result quality assurance. By the application of internal and external measures of result quality assurance the conformity assessment body is provided with an opportunity to prove its ability to the users of its services and the accreditation body. Accreditation Body of Serbia (ATS) believes that participation in inter-laboratory comparison programmes - ILC and proficiency testing - PT is important and effective means to demonstrate proficiency of the body for conformity assessment, when its activities are verified.

Although the laboratories for length and angle calibration in geodesy use the appropriate standard calibration methods, laboratory management is aware that the correctness of the results is not necessarily ensured. The laboratory work is followed by visible, expected and unpredictable problems. Some of the problems can be solved "ad-hoc", during the work process, without disturbing the quality of the obtained results and their reliability. Verifying operation, providing confidence and quality control are focused on the reliability of the results of calibration and the laboratory user confidence in the provided services.

Laboratories for length and angle calibration in geodesy, in accordance with the requirements of ISO / IEC 17025:2005 must have procedures for monitoring the quality of calibration results. Laboratory policies and procedures have the ability to prove their competency to users or the Accreditation Body of Serbia. It is important to distinguish the evaluation of competency of the laboratory by assessment of its overall work in relation to the pre-defined requirements and the evaluation of the results of laboratory participation in inter-laboratory comparison. Evaluation of the results of the laboratory participation in an inter-laboratory comparison provides the information about the technical competency of the calibration laboratory at one point, under specific conditions of one or more calibrations, within a single, specific scheme. Results of inter-laboratory comparisons allow the identification of potential problems and verification of operation when modifying the existing or introducing new methods of calibration.

\section{References}

1. ISO/IEC 17025:2005 "General requirements for the competence of testing and calibration laboratories"

2. ISO/IEC 17043:2010 "Conformity assessment General requirements for proficiency testing"

3. ISO 17123-1:2002: Optics and optical instruments Field procedures for testing geodetic and surveying instruments - Part 1: Theory

4. ISO 17123-2:2002: Optics and optical instruments Field procedures for testing geodetic and surveying instruments - Part 2: Levels.

5. ISO 17123-4:2002: Optics and optical instruments Field procedures for testing geodetic and surveying instruments - Part 4: Electrooptical distance-meters (EDM instruments).

6. ISO 17123-8:2002: Optics and optical instruments Field procedures for testing geodetic and surveying instruments - Part 8:GPS

7. Zakon o metrologiji, "Sl. glasnik RS", br. 30/2010.

8. Zakona o državnom premeru i katastru ("Službeni glasnik RS", br. 72/09 i 18/10)

9. J. Gučević, S. Delčev, V. Ogrizović, V. Vasilić, Upotreba daljinomera Mekometar ME5000 u okviru održavanja etalona, Geodetska služba, Beograd, vol. 35, br. 104, str. 5-10, (2006.)

10. J. Gučević, V. Ogrizović, O. Vasović, S. Delčev, Staking-out projected boundaries of natural property Vršac Mountains using the RTK GPS/glonass method, Glasnik Srpskog geografskog drustva, Beograd, 92(4), 79-98, (2012).

11. M. Karajović Zogović, V. Matović, V. Miletić, Interlaboratory comparisons in sanitary chemistry laboratories of the institute of public health Kragujevac, 
Web of Conferences

Festival kvaliteta 2009., Nacionalna konferencija o kvalitetu, 20. - 22. maj, Serbia, (2009). 